\title{
THE MAX LAUNCH ABORT SYSTEM - CONCEPT, FLIGHT TEST, AND EVOLUTION
}

\author{
Michael G. Gilbert ${ }^{(1)}$, PhD \\ (1) Principal Engineer, NASA Engineering and Safety Center \\ 11 Langley Blvd., MS 116,Hampton VA 23681 USA \\ Email:michael.g.gilbert@nasa.gov
}

\begin{abstract}
The NASA Engineering and Safety Center (NESC) is an independent engineering analysis and test organization providing support across the range of NASA programs. In 2007 NASA was developing the launch escape system for the Orion spacecraft that was evolved from the traditional tower-configuration escape systems used for the historic Mercury and Apollo spacecraft. The NESC was tasked, as a programmatic risk-reduction effort to develop and flight test an alternative to the Orion baseline escape system concept. This project became known as the Max Launch Abort System (MLAS), named in honor of Maxime Faget, the developer of the original Mercury escape system. Over the course of approximately two years the NESC performed conceptual and tradeoff analyses, designed and built full-scale flight test hardware, and conducted a flight test demonstration in July 2009. Since the flight test, the NESC has continued to further develop and refine the MLAS concept.
\end{abstract}

\section{INTRODUCTION}

In June 2007, the NASA Exploration Systems Mission Directorate Associate Administrator requested the NASA Engineering and Safety Center (NESC) design, develop, and test an alternative to the traditional towered-rocket launch escape system designs used for the Mercury, Apollo, and Soyuz spacecraft shown in Fig. 1. The NESC project formally became known as the "Max" Launch Abort System (MLAS), in honor of the original developer of the Mercury escape system Maxime Faget [1]. The effort was intended to provide programmatic risk-reduction for the Constellation Program (CxP) Orion Crew Exploration Vehicle (CEV) project.

The CEV project baseline Launch Abort System (LAS) development is an evolution of the Apollo towered-rocket design, Fig. 2. Unlike the Apollo LAS, the CEV LAS incorporated an attitude control motor to ensure stable flight following the escape motor burn. At the time the MLAS project was initiated, the CEV LAS was experiencing development delays related to the LAS attitude control motor. Therefore, the MLAS project was to consider escape system concepts that would not require active attitude control or stabilization following escape motor burnout.

The NESC was chosen to lead the MLAS project to take advantage of the existing NESC access to expertise and contacts from all of the NASA field centers, industry, and academia. In addition, related design and development work previously accomplished by the NESC was leveraged, including the CEV Smart Buyer Design [2], the Composite Crew Module development [3], and the Alternate Launch Abort System [4] efforts. To maximize efficient use of time and money, existing technology and off-the-shelf hardware were to be used for the flight test wherever possible. Additionally, the project enlisted the services of a mentor team and a resident engineer team. The mentor team was comprised of engineers having Apollo, Space Shuttle, and International 
Space Station (ISS) experience, while the resident engineer team consisted of early career NASA engineers assigned to MLAS to gain end-to-end flight project experience.

The paper is organized as follows. Section 2 discusses the concept development, trade studies, and system evaluations of the Objective Systems (OS) that would serve as the base design. Section 3 discusses the identification of flight test objectives and the development of a flight test vehicle to demonstrate critical aspects of a particular selected MLAS OS. Section 4 highlights the results of the July 2009 MLAS flight test, and Section 5 provides an update on the continued evolution of the MLAS concept.

\section{MLAS OBJECTIVE SYSTEM}

The original notional ideas for the MLAS system design focused on multiple externally mounted rocket motors located aft of the CEV on the shell normally covering the on-orbit service module during launch, as shown in Figure 3.

While the MLAS project was provided this configuration as a starting point and possible option, the project was not constrained to keep this configuration and was free to consider many other options to find the best approach. Configurations similar to this were previously considered, for example in [3].

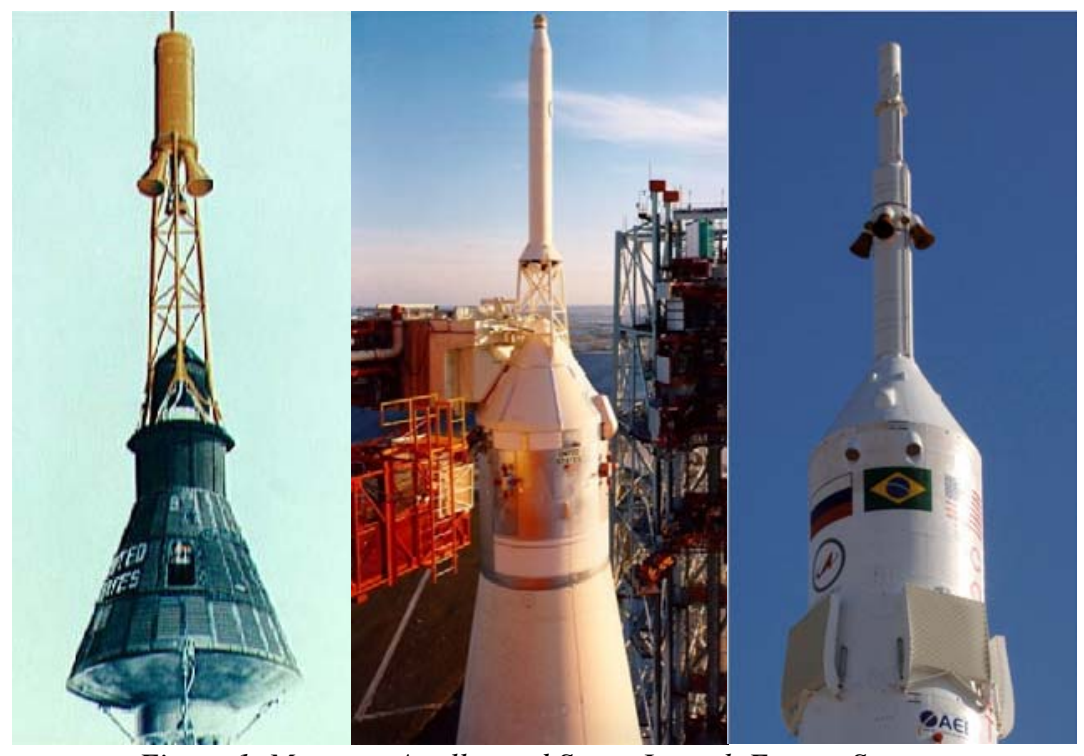

Figure 1. Mercury, Apollo, and Soyuz Launch Escape Systems 


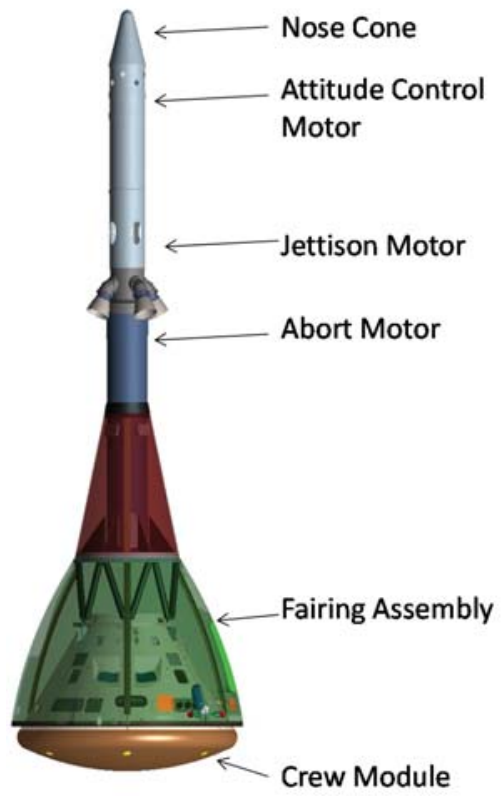

Figure 2. Baseline Orion Crew Exploration Vehicle and Launch Abort System

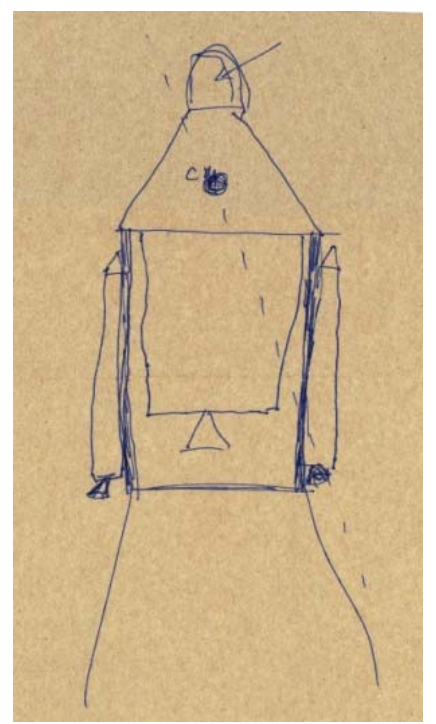

Figure 3. Originating MLAS Concept Napkin Sketch

\subsection{Objective System Escape Performance Requirements}

The high-level MLAS OS performance requirements were selected consistent with the CEV LAS performance criteria contained in [5]. These were $\underline{\text { Pad Abort }}$

- Minimum downrange travel 3300 feet

- Minimum altitude 5300 feet

- Minimum altitude at parachute deployment 4000 feet

\section{$\underline{\text { In-Flight Abort }}$}

- Minimum separation distance from Ares-I stack 175 feet within 3seconds

These criteria, along with other operational and system impacts to CEV/Ares-I were used to rank the various concepts and configurations.

\subsection{Aerodynamic Fairing Shape}

The forward shape of any launch vehicle greatly affects performance during atmospheric flight based on its aerodynamic drag characteristics. The baseline $\mathrm{CxP}$ Orion $\mathrm{CEV}$ and LAS provided a tower with numerous protuberances and discontinuous shape changes at the forward-end. Since the objective of the MLAS project was to replace the tower configuration, consideration was given to determining the desired aerodynamic shape for MLAS, with the goal to be at least no worse, in terms of drag, than the CEV baseline.

The Sears-Haack aerodynamic nosecone shape family is known to maximize internal volume with minimum drag and was selected for all MLAS configurations. The defining relationship for the SearsHaack shape is

$$
\frac{r}{R}=\left[1-\left[1-\frac{x^{-2}}{L}\right]^{-3 / 4}\right.
$$

where $R$ and $L$ are the desired maximum radius and desired length respectively, and $r$ is the shape radius at the given $x$ (axial) location. 
The impact of removing the tower from the integrated launch vehicle in favor of a Sears-Haack R/L $=1 / 2$ nose shape was evaluated using CFD methods. To isolate the tower aerodynamic effect, the same Sears-Haack forward fairing was used in both CFD models as shown in Figure 4.

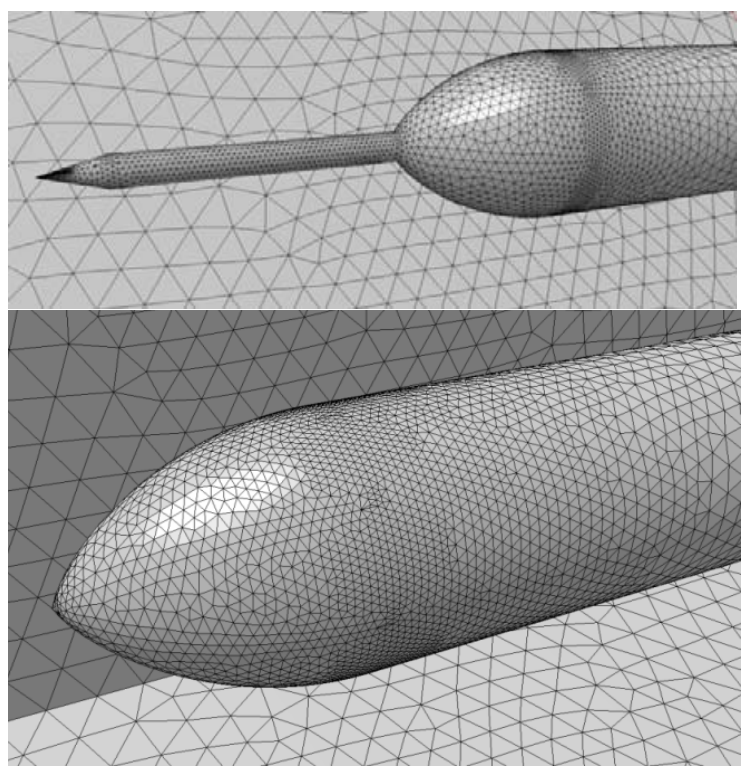

Figure 4.CFD Models for Evaluation of Tower Effects on the Ares-I Launch Vehicle: (top: $L V$ with tower), (bottom: $L V$ without tower)

The CFD computed drag results showed an approximate factor of 3 reduction in the axial drag coefficient, and a $7 \%$ reduction in aerodynamically induced bending moment at the base of the Ares- 1 frustum.

\subsection{Escape Motor Sizing}

The baseline Constellation program CEV LAS escape motor provides approximately $15 g$ 's of acceleration for approximately 2 seconds and then tails off to zero thrust over approximately another second. Total impulse of the motor is about $1.0 \times 10^{6} \mathrm{lb}$ sec. Since the MLAS concepts called for multiple motors, the initial approach to sizing the MLAS OS escape motors was to simply divide the CEV LAS total impulse by the number of MLAS motors. A survey of existing U.S. solid rocket motors was then conducted to identify candidate motor characteristics, such as thrust level and burn time, that provided the desired impulse.

U.S. Navy Standard Missile boosters MK12, MK-70, and MK-72 provide the right total impulse with 4-6 motors, although they were longer burning ( $\sim \sec$ ) with a corresponding lower peak thrust. The MK-12 and MK-70 have the same overall dimensions and more closely match the desired length of the aft fairing than the MK-72. The MK-70 motor thrust profile was used to evaluate the performance of the MLAS concepts, and was the motor actually used for the flight test.

It was assumed throughout the MLAS OS studies that the OS would ultimately utilize escape motors designed to meet specific thrust/impulse requirements with thrust-vector-control or TVC. This was assumed because trajectory control and compensation for variations in startup and shutdown thrust among motors would be needed during the high-thrust escape.

\subsection{Side-Mounted Escape Motor Concept Studies}

The first consideration for MLAS concept development was the aft-fairing or sidemounted escape motor configuration as indicated in Fig. 3. From this starting point, the number and placement of escape rocket motors, escape separation dynamics, aerodynamic stability during coast following escape motor burnout, CEV extraction, and operational considerations and impacts to the CEV/ARES-I vehicle were analyzed.

\subsubsection{Concept}

Figure 5 shows a side-mount concept utilizing 6 escape motors uniformly distributed uniformly around an aftaerodynamic shell encapsulating the CEV service module. In this concept, the thrust 
loads of the escape motors are transferred to the forward-fairing from the aft fairing, and then to the crew module. The crew module attachment points are the same as for the baseline CEV LAS, such that no changes to the crew module structure would be required to accommodate MLAS. The fins mounted on each of the motor housings provide $\sim 10 \%$ positive static aerodynamic margin such that active attitude control during coasting flight is not necessary. Without fins, the configuration would be statically unstable.

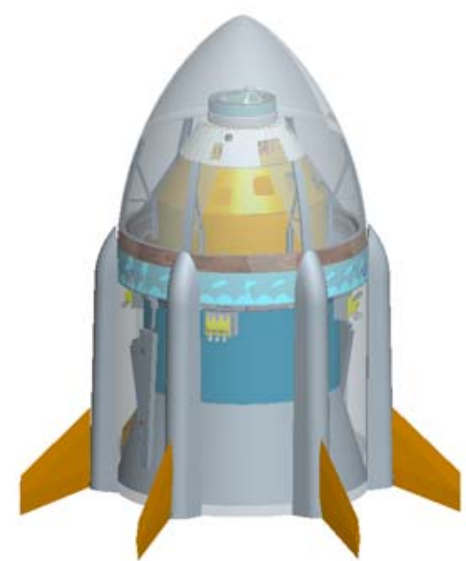

Figure 5. Final Side-Mounted Escape Motor MLAS Concept with Aerodynamic Fins for Coasting Flight Stability

\subsubsection{Concept-of-Operations}

The side-mount OS concept-of-operations for pad-escape is shown in Figure 6. The operations concept for low- and midaltitude escapes, up to nominal flight fairing jettison, are similar. During nominal flight, the aerodynamic fairing is removed by the escape motors shortly after second stage ignition.

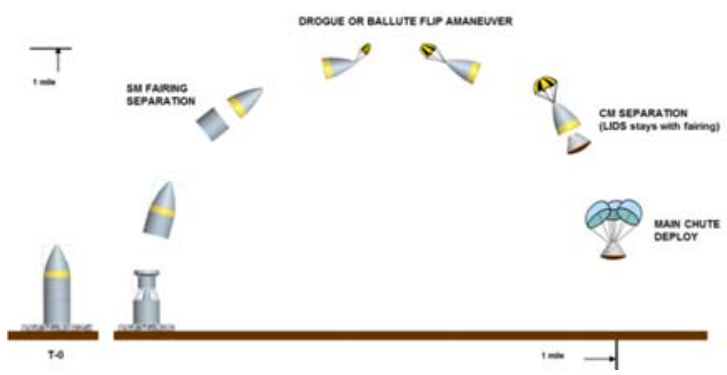

Figure 6. Side-Mounted Configuration Concept-ofOperations (Pad-Abort Shown, Low- and MidAltitude Similar)

At the start of the escape sequence, the structural connection between the CEV crew module and avionics ring/service module is severed and the escape motors ignite. The MLAS fairing and crew module then separate from the launch vehicle, with the aft-portion of the MLAS fairing sliding up over the service module and avionics ring. Once the escape motors burn-out, the escape system coasts to predefined flight conditions where the aftfairing is released and drogue parachutes are deployed to turn the forwardfairing/crew module around to crew module heat shield forward. The forward MLAS fairing is then separated from the crew module, allowing the crew module to use its primary recovery parachute systems to safely land the crew. The duration of the coast period is dependent on the launch vehicle flight conditions at the time of escape initiation, driven by the allowable flight conditions for the crew module parachute recovery system. Thus, for higher altitude, higher velocity escapes, the MLAS/crew module configuration would coast longer before reorientation and fairing release.

\subsubsection{Concept Evaluation}

The OS configuration shown in Figure 5 meets the basic performance requirements of Section 2.1. However, while the escape performance requirements were satisfied, several other potential system and operation issues were identified. These included

a) Open Aft Shell Structure and Dynamics: The structural requirements on the aftfairing are more severe than for the baseline CEV LAS configuration. The aftfairing is no longer simply an aerodynamic covering for the CEV service module, but must carry propulsive and aerodynamic loads during escape and recovery. 
b) Separation Dynamics: During the initial escape motion the aft-fairing moves over the CEV service module and avionics ring Co-axial alignment of the CEV/MLAS combination must be maintained until the aft-fairing clears the service module and avionics ring. Maintaining this alignment would likely require the addition of structural guide rails to the service module.

c) Numbers of Separation Joints: Compared to the baseline CEV LAS, the side-mounted motor concept requires more separation and release joints and mechanisms.

c) Estimated Weight: The weight estimate for this concept, before weight growth allowances, was approximately 33,000lbs including CEV. This was about 600lbs heavier than the baseline LAS.

d) Fin Impact: The addition of fins on the forward end of the launch vehicle would impact the aerodynamic loads acting on the launch stack, and could negate the benefits of removing the tower.

Based on the the indentified design impacts with the side-mount escape motor MLAS configuration, the MLAS project decided to consider an alternative concept that might reduce or eliminate these concerns.

\section{$2.5 \quad$ Forward-Fairing Escape Motor Concept}

Mounted

A second set of MLAS concept options were developed based on eliminating differences between the CEV/LAS interfaces and what would be required to implement MLAS. This led to placement of the escape motors in the forward-fairing along side the CEV and not using an aft fairing. In these concepts, the number and location of the separation joints and mechanisms for both nominal ascent and escape are the same as for the baseline LAS system. In addition, the overall length of the MLAS system was cut approximately in half compared to the side-mount configurations.

\subsubsection{Concept}

Fig. 7 illustrates the forward-fairing mounted escape motor MLAS concept. Six escape motors are arranged around the forward-fairing along side the CEV, with small pods or fairings covering the protruding aft-end of the each motor. It was again assumed that the operational MLAS would use design specific motors with thrust-vector-control for the escape manuever, to ensure a proper escape trajectory.

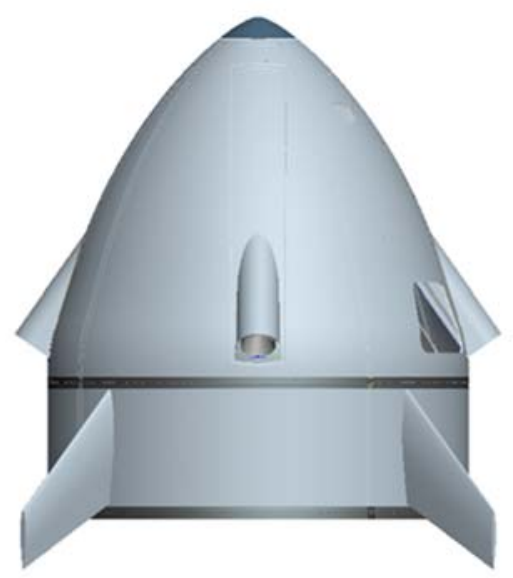

Figure 7. Forward-Fairing Mounted Escape Motor Concept Configuration

In this concept, the escape motor loads are transferred via the forward-fairing to the exsiting CEV LAS structural attachment points, reducing the necessity to make structural changes to the CEV to accommodate MLAS. As with the sidemount motor MLAS concepts, this configuration is aerodynamically statically unstable without fins. Fin size, number, and placement was adjusted to minimize size (and the resulting impact on launch vehicle dynamics) and the length of a short aft fairing while providing $~ 10 \%$ positive static margin.. With the fin size and aft fairing length shown, there is no structural 
impact to the service module, such as the addition of guide rails, as with the aftmounted motor concept. The configuration of Fig. 7 became the basis of the MLAS flight test.

\subsubsection{Concept Evaluation}

The OS configuration shown in Fig. 7 also satisfies the basic performance requirements of Section 2.1.

a) Fin Impact: This concept also has a significant impact to the launch vehicle from the addition of aerodynamic fins near the front. Noting that the Russian Soyuz spacecraft uses deployable grid fins for aerodynamic stability during crew escape operations (see Fig.1, right), an operational MLAS configuration featuring deployable, aft-swept grid fins without the cylindrical addon section was envisioned. This configuration is discussed in more detail in Section 5.

b) Weight: The final weight estimate for this concept, without weight growth allowance, was approximately 29,000lbs including the $19,000 \mathrm{lb} \mathrm{CEV}$, or about 3400lbs lighter than the baseline LAS.

\subsection{MLAS Flight Test Vehicle}

\subsection{Primary Flight Test Objectives}

The critical aspects of the Fig.7 OS concept selected for flight demonstration were passive aerodynamic stability, reorientation from nose-forward flight to crew module-heat shield forward flight, and removal of the MLAS fairing to allow for crew module recovery via parachutes. Demonstration of the forward-fairing mounted escape motors was not included for cost and schedule reasons.

\subsection{Flight Test Vehicle Configuration}

Fig. 8 illustrates the final, full-scale, flight test vehicle configuration and major components.

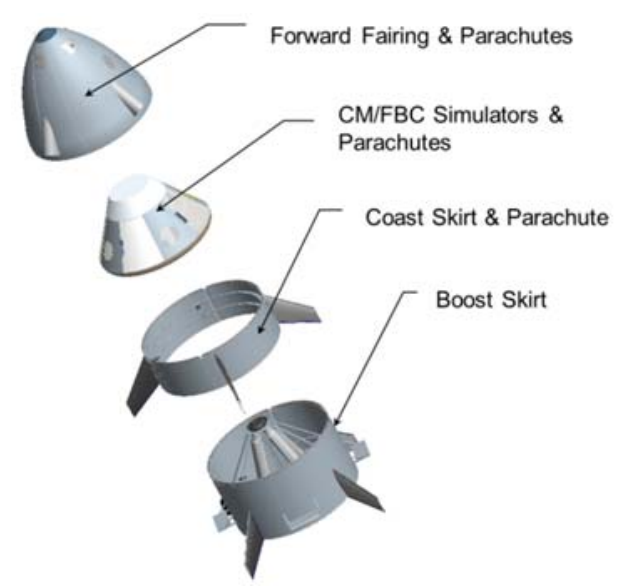

Figure 8. Flight Test Vehicle: (top Integrated Vehicle in Pre-Flight Configuration and (bottom

Expanded View Showing Major Components)

As shown, the Forward-Faring \& Parachutes, the Crew Module (CM) and Forward-Bay Cover (FBS), and the Coast Skirt \& Parachutes (CS) replicate the MLAS OS system, while the Boost Skirt (BS) provides the escape system propulsion in lieu of forward-fairing mounted motors. The Boost Skirt element was implemented to achieve desired flight test conditions using four readily available, fixed-nozzle MK-12 solid rocket motors. Attempting to fly the fixed nozzle MK-12 motors in the forward fairing would have required cross-ducting of the motors to reduce startup and burn-out transients. As previously mentioned, an operational MLAS would utilize thrust-vectored escape motors to overcome the transients.

A steel boilerplate replica of an Orion crew module was fabricated for the flight test. This replica was full-scale and weighted $\sim 16000$ lbs. The forward-fairing, coast skirt, and boost skirt structures were purpose designed and built by Northrup Grumman Corp. An aluminum truss structure with adjustable support struts was also designed and fabricated by Northrup Grumman to align and support the MK-12 
motors and transfer the launch loads to the outer fairings and the crew module.

\subsection{Secondary Flight Test Objective}

At the request of the Orion CEV project, an alternative configuration to the baseline CEV parachute recovery system was flown to slow the descent of the MLAS crew module simulator at the end of the MLAS flight test. Fig. 9 shows the main crew module recovery parachute system mounted in the simulated Forward-Bay Cover (FBC). Unlike the baseline Orion main recovery parachute system with drogue chute deployment of the main parachutes, the MLAS tested configuration mounted the parachutes in the forward-bay cover directly and pulled the parachutes out when the FBC released from the crew module.

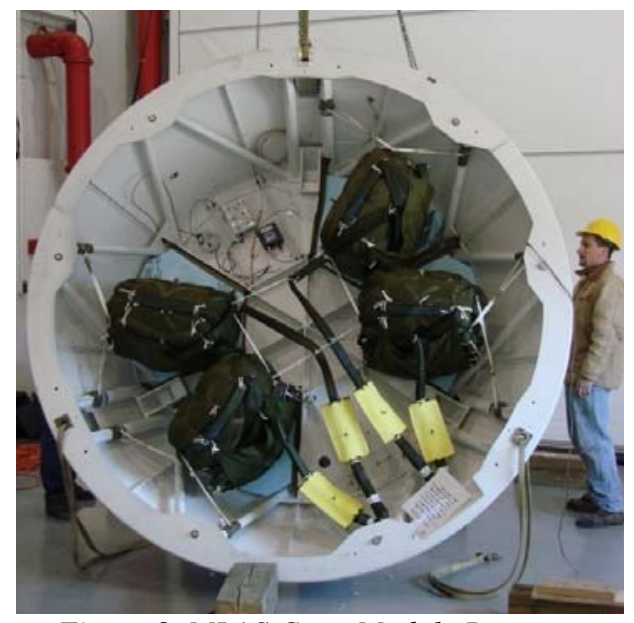

Figure 9. MLAS Crew Module Recovery Parachutes in Forward-Bay Cover

\subsection{MLAS Pad-Abort Flight Test and Results}

\subsection{Flight Test of July 2009}

The MLAS FTV was launched from the NASA Wallops Flight Facility on July 8, 2009 at approximately 6:30am. Fig. 10 shows the flight test event sequence up to the completion of the primary flight test objectives. The secondary flight test sequence began once the crew module was released from the forward-fairing.

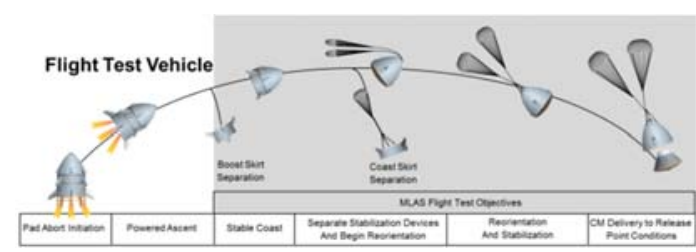

Figure 10. MLAS Flight Test Events (Expand)

Fig. 11 shows the MLAS flight test vehicle during the boost phase to the desired flight primary flight test conditions.

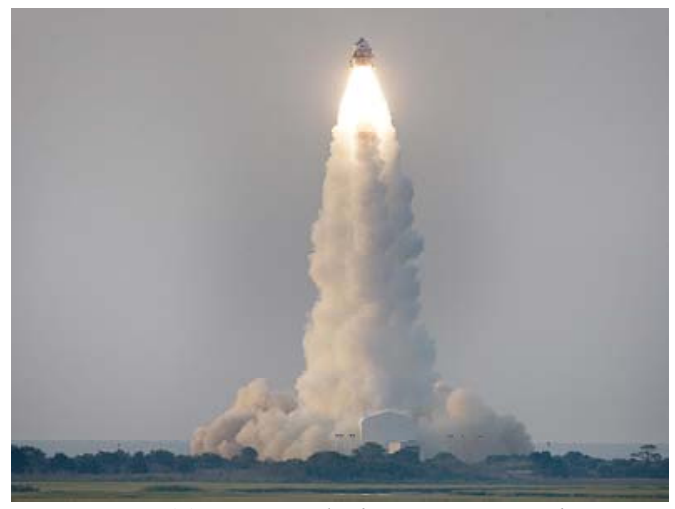

Figure 11. MLAS Flight Test Boost Phase

Fig. 12 shows the MLAS in the flight test condition undergoing stable coast flight after release of the boost skirt. This was the first primary flight test objective.

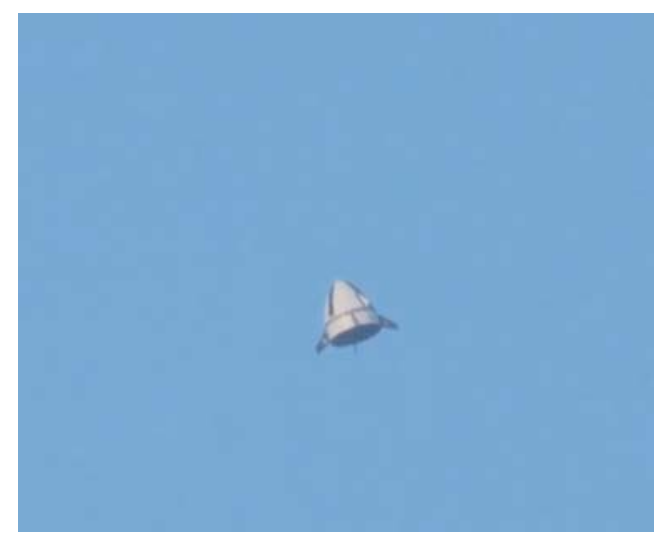

Figure 12. MLAS in stable, unpowered coasting flight

Fig. 13 shows the deployed reorientation parachutes and the turning around of the crew module/forward-fairing combination from a nose forward flight condition to a 
crew module heat shield forward condition.

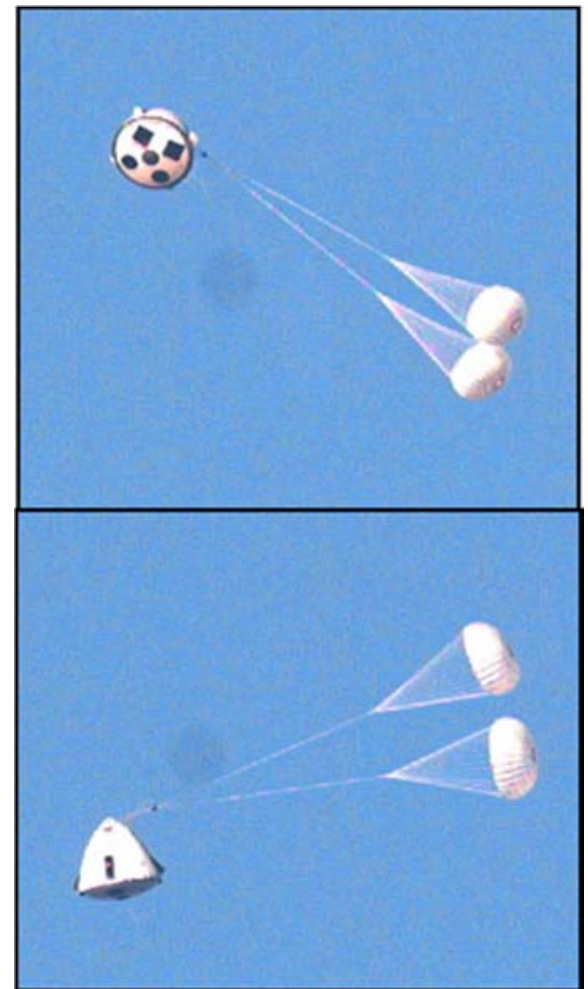

Figure 13. MLAS During Reorientation Following Coast Skirt Separation

Fig. 14 shows the MLAS flight test vehicle at the completion of the primary and secondary flight test objectives. The crew module is descending to a water landing on the main recovery parachutes, with the forward-fairing and crew module forward bay cover behind.

\subsection{Flight Test Results}

The MLAS flight test vehicle achieved all stated flight performance requirements and constraints during the July 8, 2009 flight test. Figs. 15 and 16 show comparisons of pre-flight trajectory and performance predictions to measured flight data. These measured trajectory results are within one standard deviation of the fully dispersed Monte Carlo simulations about the nominal pre-flight trajectory.

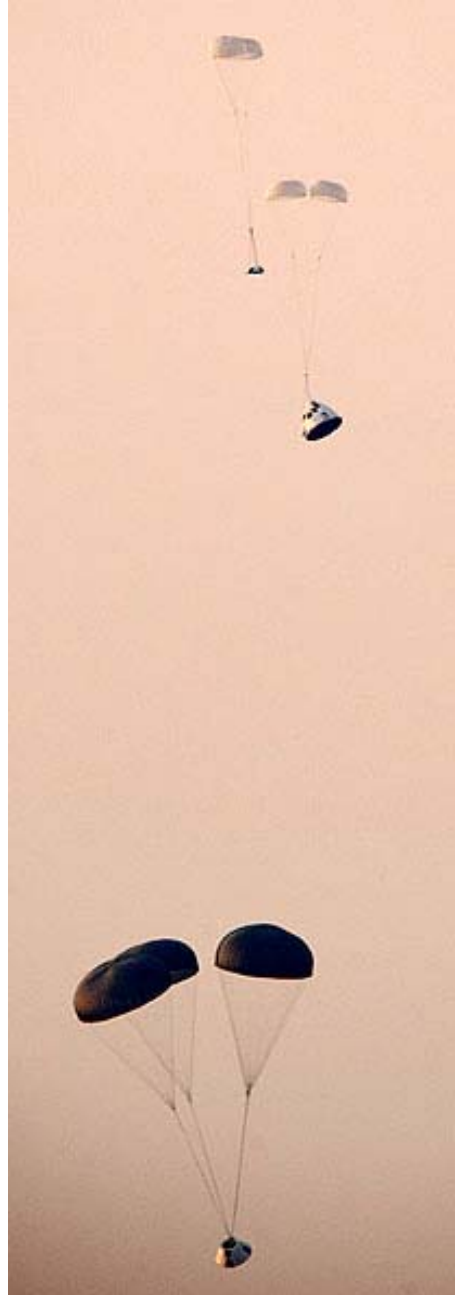

Figure 14. MLAS at the completion of all primary and secondary flight test objectives.

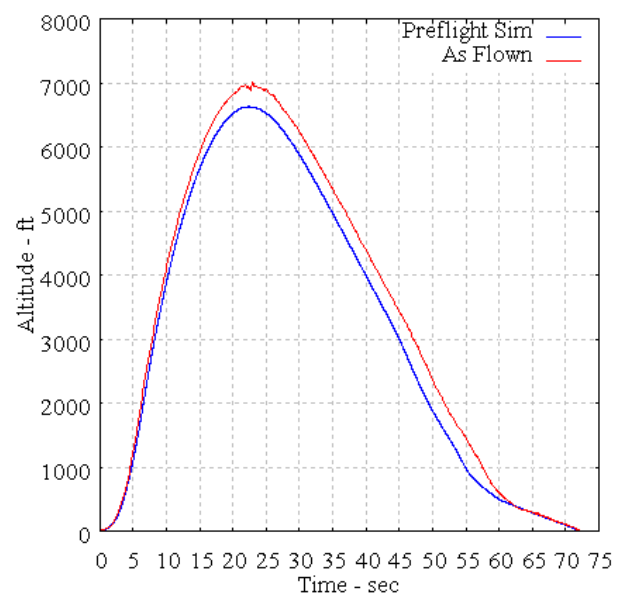

Figure 15. Comparison of Pre-Flight Altitude vs. Time Predictions with Flight Data 


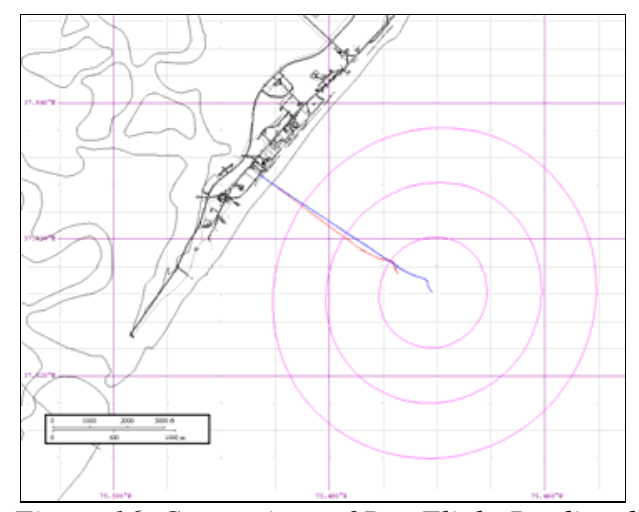

Figure 16. Comparison of Pre-Flight Predicted Ground Track with Flight Data. Circles Indicate

Pre-Flight Standard Deviations of Dispersed Monte Carlo Simulations.

The predicted aerodynamic stability of the MLAS flight test vehicle during coasting flight matched similarly well with the measured flight stability data as shown in Fig. 17.

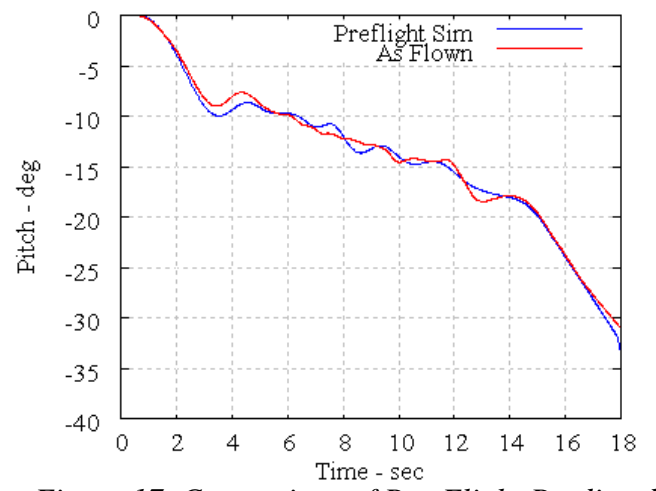

Figure 17. Comparison of Pre-Flight Predicted

Pitch Attitude vs. Time with Flight Test Data

\subsection{MLAS Design Evolution}

As indicated in Sections 2.4.3 and 2.5.2 the MLAS Objective system concepts with stabilizing aerodynamic fins will impact the launch vehicle flight dynamics and structural design loads. Noting that the Soyuz LAS uses deployable aerodynamic grid fins for post-escape stabilization (see Fig. 1), an MLAS concept using deployable swept grid fins was investigated. The evolved concept is shown in Fig. 18, and the operations sequence for this concept is shown in Fig. 19. Four deployable grid fins are initially folded into recesses in the forward fairing between the escape motors and covered by smooth covers. At escape initiation, the covers are jettisoned and the grid fins are deployed aft to the desired aft-sweep angle. After escape motor burnout and stable coasting to the desired recovery flight conditions, the grid fins are jettisoned and the crew module/forward fairing reoriented with mortar fired parachutes as shown in Fig. 20.

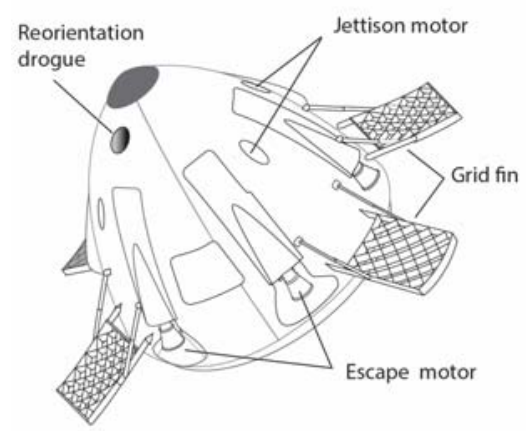

Figure 19. Evolved MLAS Concept

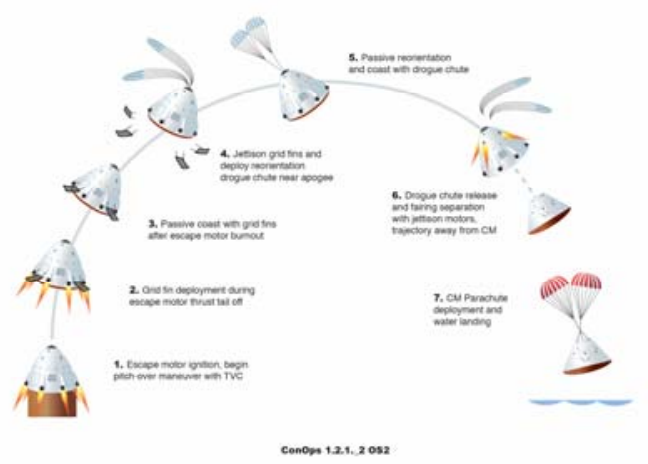

Figure 20. Evolved MLAS Operational Sequence (Endoatmospheric)(Expand)

It must be emphasized that the statically stable MLAS concepts are useable only when there is sufficient atmosphere to make the fins effective.

\section{References}

